\title{
ORIGEN ROMANO DE LA ENFITEUSIS EN LAS PARTIDAS
}

\author{
JOSÉ MARÍA ORTUÑO SÁNCHEZ-PEDREÑO \\ Universidad de Murcia
}

\section{LA ENFITEUSIS EN DERECHO ROMANO ${ }^{1}$}

El origen del derecho real de enfiteusis parece ser una derivación de los arrendamientos a largo plazo, a partir de instituciones distintas:

- Por una parte, de la conductio agri vectigalis, arrendamiento hecho a los particulares de los agri vectigales, especialmente de los municipios, pero también del Estado, de las colonias, templos o colegios sacerdotales. A cambio del pago de un canon periódico, al arrendatario le era concedida, perpetuamente o durante un largo período de tiempo, la disponibilidad del fundo. A dicho arrendatario, el pretor concedió una acción real, por lo que la conductio agri vectigalis pasó a constituir un derecho real pretorio transmisible.

- Por otra parte, parece que institutos de origen extranjero, vigentes desde hacía siglos en las provincias, influyeron asimismo en el origen de esta institución. En los territorios helenísticos, ya desde el siglo $\mathrm{V}$ a.C. se concedían a particulares en arrendamiento perpetuo fundos, generalmente sin cultivar, con la obligación por parte de dichos particulares de roturarlos, cultivarlos y pagar un canon periódicamente.

1 Sobre la enfiteusis en Derecho Romano pueden consultarse las siguientes obras: S. PIVANO, I contratti agrari nel Medioevo, Torino, 1904; G. SEGRE, Dell'enfiteusi secondo il diritto civile e le leggi speciali (Riv.ital.sc.giurid.), 1908, n. 45; R. TRIFONE, Feudi e demani, Napoli, 1909; VALORI, Delle prestazioni enfiteutiche nelle varie parti d'ltalia, Torino, 1909; F. FILOMUSI GUELFI, Dirittirealiad uso dilezioni, Roma, 1910; L. MAURO, Il contratto di enfiteusi nel diritto comune, Napoli, 1912; GLUCK, Commentario alle Pandette, trad. G. Segre, v.VI,3; V. SIMONCELLI, Della enfiteusi, Napoli-Torino, 1922; N. COVIELLO, La trascrizione, Napoli-Torino, 1924; WINSCHEID, Diritto delle Pandette, trad. FADDA-BENSA, Torino, 1926; A. CHERCHI, La natura giuridica dell'enfiteusi, Riv.dir.civ., 1933, 23; CENCETTI, Il contratto di enfiteusi nella dottrina dei glossatori e commentatori, Bologna, 1933; P. BONFANTE, Istituzioni di diritto romano, $6^{\text {a }}$ ed., Milano; L. CARIOTTA-FERRARA, L'enfiteusi (Trattato di diritto civile), Torino, 1950; ORLANDO CASCIO, Studi sull'enfiteusi, Ann.sem.Palermo, 1951; G. CARRARA, I contratti agrari, Torino, 1952; DE RUGGIERO-MAROI, Istituzioni di diritto privatto, Messina, 1952; DE MARTINO, Ager privatus vectigalisque, Studi de Francisci, Milano, 1956; BRANCA, v. Enfiteusi, NNDI, 1957; BOVE, Ricerche sugli agri vectigales, Napoli, 1960; GALLO, Discipline giuridica e costruzione dogmatica nella locatio degli agri vectigales, SDHI, 1964.30; WIEACKER, Agri vectigales, LABEO, 1964, 10; P. VACCARI, V. Enfiteusi (Storia), ED, 1965; LEVI, Genesi della centuriato e dell'ager vectigalis. La parola del passato, 1968, 129; STERCKX, Appíen. Plutarque et les premiers reglements de modo agrorum, RIDA, 1969, 16. 
En el siglo IV d.C. nos consta la aparición del ius emphyteuticarium y del ius perpetuum, modelados sobre la base de la conductio agri vectigalis, teniendo el primero por objeto los funda patrimoniales, o sea, pertenecientes al patrimonio del Emperador, mientras el ius perpetuum recaía sobre bienes del fisco imperial. El ius emphyteuticarium era una concesión a largo plazo, renovable a su cese; el ius perpetuum era una concesión perpetua. Al enfiteuta se le imponía también la obligación de cultivo que no solía imponérsele al perpetuario; de ahí el nombre de emphyteusis (de $\phi v \tau \varepsilon v ́ \omega$, plantar), por la obligación de plantación que incumbía al concesionario, a imitación de lo que sucedía en contratos análogos de tierras incultas en Grecia.

En el siglo V d.C., ius perpetuum y ius emphyteuticarium se funden en la única figura de la enfiteusis, que encuentra una reglamentación unitaria y precisa en una Constitución imperial del Emperador Zenón, que hay que datarla entre los años 476 y $484^{2}$. Dicha Constitución imperial se recoge en el Código justinianeo, 4.66.1, dentro del título de emphyteutico iure ${ }^{3}$. En ella se prescribe que el acuerdo entre propietario y enfiteuta, dirigido a conceder a éste la disponibilidad total y exclusiva del fundo a cambio de la prestación de un pago periódico invariable, no debe ser entendido ni como arrendamiento ni como venta, sino como un negocio independiente, con concepto y definición propios, constitutivo de un ius emphyteuticarium sobre el fundo:

«Ius emphyteuticarium neque conductionis neque alienationis esse titulis addicendum, sed hoc ius tertium sit constitutum ab utriusque memoratorum contractuum societate seu similitudine separatum, conceptionem definitionemque habere propriam et iustum esse validumque contractum, in quo cuncta, quae inter utrasque contrahentium partes super omnibus vel etiam fortuitis casibus pactionibus scriptura interveniente habitis placuerint, firma illibataque perpetua stabilitate modis omnibus debeant custodiri...».

\footnotetext{
2 CORBELlA, A., Historia jurídica de las diferentes especies de censos, Madrid, 1892, p. 180.

3 C.4.66.1: «Ius emphyteuticarium neque conductionis neque alienationis esse titulis addicendum, sed hoc ius tertium sit constitutum ab utriusque memoratorum contractuum societate seu similitudine separatum, conceptionem definitionemque habere propriam et iustum esse validumque contractum, in quo cuncta, quae inter utrasque contrahentium partes super omnibus vel etiam fortuitis casibus pactionibus scriptura interveniente habitis placuerint, firma illibataque perpetua stabilitate modis omnibus debeant custodiri: ita ut, si interdum ea, quae fortuitis casibus sicut eveniunt, pactorum non fuerint conventione concepta, si quidem tanta emerserit clades, quae prorsus etiam ipsius rei quae per emphyteusin data est facit interitum, hoc non emphyteuticario, cui nihil reliquum mansit, sed rei domino, qui, quod fatalitate ingruebat, etiam nullo intercedente contractu habiturus fuerat, imputetur: sin vero particulare vel aliud leve damnum contigerit, ex quo non ipsa rei penitus laedatur substantia, hoc emphyteuticarius suis partibus non dubitet adscribendum».
} 
Añade la Constitución objeto de nuestro estudio que el perjuicio derivado de una calamidad que causa la pérdida total de la cosa ha de soportarlo el propietario de la misma, pero un perjuicio parcial, que no lesione la sustancia de la cosa, no extingue la obligación del enfiteuta:

«... ita ut, si interdum ea, quae fortuitis casibus sicut eveniunt, pactorum non fuerint conventione concepta, si quidem tanta emerserit clades, quae prorsus etiam ipsius rei quae per emphyteusin data est facit interitum, hoc non emphyteuticario, cui nihil reliquum mansit, sed rei domino, qui, quod fatalitate ingruebat, etiam nullo intercedente contractu habiturus fuerat, imputetur: sin vero particulare vel aliud leve damnum contigerit, ex quo non ipsa rei penitus laedatur substantia, hoc emphyteuticarius suis partibus non dubitet adscribendum».

Las Instituciones de Justiniano 3.24.3 también establecen la naturaleza propia del contrato de enfiteusis ${ }^{4}$. Y denotan cómo la Constitución imperial promulgada por el Emperador Zenón puso fin a las dudas que se suscitaban entre los juristas sobre cómo había de calificarse este derecho, estimándose por algunos arrendamiento y por otros venta. También recoge este pasaje que la obligación del enfiteuta no desaparece por cambios o por deterioro del fundo, excepto en el caso de destrucción total:

«... Sed talis contractus quia inter veteres dubitabatur, et a quibusdam locatio, a quibusdam venditio existimabatur: Iex Zenoniana lata est, quae emphyteuseos contractui propriam statuit naturam neque ad locationem neque ad venditionem inclinantem, sed suis pactionibus fulciendam, et si quidem aliquid pactum fuerit, hoc ita optinere, ac si naturalis esset contractus, sin autem nihil de periculo rei fuerit pactum, tunc si quidem totius interitus acceserit ad dominum super hoc redundare periculum, sin particularis, ad emphyteuticarium huiusmodi damnum venire. Quo iure utimur».

4 Inst. 3.24.3: «Adeo autem familiaritatem aliquam inter se habere videntur emptio et venditio, item locatio vel conductio, ut in quibusdam causis quaeri soleat, utrum emptio et venditio contrahatur, an locatio et conductio. Ut ecce de praediis, quae perpetuo quibusdam fruenda traduntur, id est ut, quamdiu pensio sive reditus pro his domino praestetur, neque ipsi conductori, neque heredi eius, cuive conductor heresve eius id praedium vendiderit aut donaverit aut dotis nomine dederit aliove quoquo modo alienaverit, auferre liceat. Sed talis contractus quia inter veteres dubitabatur, et a quibusdam locatio, a quibusdam venditio existimabatur: lex Zenoniana lata est, quae emphyteuseos contractui propriam statuit naturam neque ad locationem neque ad venditionem inclinantem, sed suis pactionibus fulciendam, et si quidem aliquid pactum fuerit, hoc ita optinere, ac si naturalis esset contractus, sin autem nihil de periculo rei fuerit pactum, tunc si quidem totius rei interitus acceserit ad dominum super hoc redundare periculum, sin particularis, ad emphyteuticarium huiusmodi damnum venire. Quo iure utimur». 
La enfiteusis puede constituirse por cualquier acuerdo entre las partes que tenga tal objeto que haga que inmediatamente surja la relación real, sin necesidad de actos posteriores. Las partes pueden acordar la extensión de los derechos y obligaciones de las partes, pero no la falta de pago del canon, que es un elemento esencial.

El enfiteuta puede ejercer sobre el fundo las facultades propias del propietario; puede darlo en usufructo, constituir sobre él servidumbres urbanas y rústicas o someterlo a hipoteca. Tiene el derecho al rescate (llamado también liberación), esto es, puede adquirir la propiedad plena del fundo pagando al propietario la suma correspondiente a la capitalización del canon. Está obligado al pago de la prestación periódica invariable que hayan acordado.

Puede el enfiteuta ceder a otros su derecho. Pero, como prescribe una Constitución imperial del Emperador Justiniano del año 530, recogida en el Código justinianeo, 4.66.3, a falta de pacto que disponga algo distinto, no le es lícito al enfiteuta transferir su derecho sin consentimiento del propietario 5 . En caso de que el enfiteuta quiera vender su derecho ha de preavisar al dueño de ello e indicarle cuánto quieren darle por dicha venta. El propietario goza del derecho de prelación (ius praelationis o ius protimeseos), esto es, puede hacer que cese la enfiteusis sobre su fundo pagando la cantidad que pretenden dar al enfiteuta. Si transcurren

5 C.4.66.3: «Cum dubitabatur, utrum emphyteuta debeat cum domini voluntate suas meliorationes, quae Graeco vocabulo emponemata dicuntur, alienare vel ius emphyteuticum in alium transferre, an eius expectare consensum, sancimus, si quidem emphyteuticum instrumentum super hoc casu aliquas pactiones habeat, eas observari: sin autem nullo modo huiusmodi pactio posita est vel forte instrumentum emphyteuseos perditum est, minime licere emphyteutae sine consensu domini suas meliorationes aliis vendere vel ius emphyteuticum transferre. Sed ne hac occasione accepta domini minime concedant emphyteutas suos accipere pretia meliorationum quae invenerint, sed eos deludant et ex hoc commodum emphyteutae depereat, disponimus attestationem domino transmitti et praedicere, quantum pretium ab alio re vera accipit. Et si quidem dominus hoc dare maluerit et tantam praestare quantitatem, quantam ipsa veritate emphyteuta ab alio accipere potest, ipsum dominum omnimodo haec comparare. Sin autem duorum mensuum spatium fuerit emensum et dominus hoc facere noluerit, licentia emphyteutae detur, ubi voluerit, et sine consensu domini suas meliorationes vendere, his tamen personis, quae non solent in emphyteuticis contractibus vetari ad huiusmodi venire emptionem: necessitatem autem habere dominos, si aliis melioratio secundum praefatum modum vendita sit, accipere emphyteutam vel, ius emphyteuticum ad personas non prohibitas sed concessas et idoneas ad solvendum emphyteuticum canonem transponere si emphyteuta maluerit, non contradicere, sed novum emphyteutam in possessionem suscipere, non per conductorem nec per procuratorem, sed ipsos dominos per se vel per litteras suas vel, si hoc non potuerint vel noluerint, per depositionem in hac quidem civitate apud virum clarissimum magistrum censuum vel praesentibus tabulariis per attestationem, in provinciis autem per praesides vel defensores celebrandam. Et ne avaritia tenti domini magnam molem pecuniarum propter hoc efflagitent, quod usque ad praesens tempus perpetrari cognovimus, non amplius eis liceat pro subscriptione vel depositione nisi quiquagesimam partem pretii vel aestimationis loci, qui ad aliam personam transfertur, accipere. Sin autem novum emphyteutam vel emptorem meliorationis suscipere minime dominus maluerit et attestatione facta intra duos menses hoc facere supersederit, licere emphyteutae et non consentientibus dominis ad alios ius suum vel emponemata transferre. Sin autem aliter fuerit versatus, quam nostra constitutio disposuit, iure emphyteutico cadat». 
dos meses sin que el dueño manifieste su intención de comprarlo, el enfiteuta puede vender su derecho enfitéutico a cualquier otra persona, con tal de que no sea de los prohibidos por la ley, y el propietario ha de aceptar al nuevo enfiteuta, siempre que sea persona idónea para pagar el canon. Pero para que, tentados los dueños por la avaricia, no exijan por tal traspaso grandes cantidades de dinero (como sabemos - dice el pasaje del Código- que ha ocurrido hasta el presente) se prohibe que cobren por su firma más de la quincuagésima parte del precio o de la estimación de la finca (esta cuota recibió durante la Edad Media el nombre de laudemium):

«... sin autem nullo modo huiusmodi pactio posita est vel forte instrumentum emphyteuseos perditum est, minime licere emphyteutae sine consensu domini suas meliorationes aliis vendere vel ius emphyteuticum transferre. Sed ne hac occasione accepta domini minime concedant emphyteutas suos accipere pretia meliorationum quae invenerint, sed eos deludant et ex hoc commodum emphyteutae depereat, disponimus attestationem domino transmitti et praedicere, quantum pretium ab alio re vera accipit. Et si quidem dominus hoc dare maluerit et tantam praestare quantitatem, quantam ipsa veritate emphyteuta $a b$ alio accipere potest, ipsum dominum omnimodo haec comparare. Sin autem duorum mensuum spatium fuerit emensum et dominus hoc facere noluerit, licentia emphyteutae detur, ubi voluerit, et sine consensu domini suas meliorationes vendere, his tamen personis, quae non solent in emphyteuticis contractibus vetari ad huiusmodi venire emptionem... Et ne avaritia tenti domini magnam molem pecuniarum propter hoc efflagitent, quod usque ad praesens tempus perpetrari cognovimus, non amplius eis liceat pro subscriptione vel depositione, nisi quinquagesimam partem pretii vel aestimationis loci, qui ad aliam personam transfertur, accipere...»

El enfiteuta puede proceder en defensa de su derecho con la reivindicatio utilis, con la actio confessoria utilis y con la actio negatoria, junto con los medios de defensa de las relaciones de vecindad y, por supuesto, con los interdictos posesorios.

La enfiteusis cesa por no notificar el enfiteuta al propietario la venta de su derecho, por el ejercicio del ius praelationis por parte del dueño, por destrucción total del fundo, por confusión, por el ejercicio del rescate por el enfiteuta, por prescripción del derecho (lo que tiene lugar por la usucapio libertatis: el dueño realiza un acto contrario al ejercicio de la enfiteusis y dispone plenamente del fundo sin oposición del enfiteuta durante el tiempo necesario para la usucapión). Hay que destacar, como causa de extinción de la enfiteusis, la que se recoge en 
una Constitución imperial de Justiniano del año 529, contenida en C.4.66.2 $2^{6}$. En ella se prescribe que, no habiéndose pactado nada al respecto, si durante tres años el enfiteuta no paga el canon al propietario o no le entrega las cartas de pago de los tributos, puede el propietario expulsar al enfiteuta:

«... Sin autem nihil super hoc capitulo fuerit pactum, sed per totum triennium neque pecunias solverit, neque apochas domino tributorum reddiderit, volenti ei licere eum a praediis emphyteuticariis repellere...»

Tratándose de bienes eclesiásticos o de hospicios de pobres, el plazo de impago del canon causante de la extinción de la enfiteusis se reduce a dos años. Así lo establece la Novela 7, promulgada el año 535 por el Emperador Justiniano, en su cap. 3.2:

«Scire autem emphyteotas convenit quia, si biennio continuo non exolverint emphyteoticum canonem (hoc enim tempus pro triennio aliorum hominum sufficere ad casum ecclesiasticarum aut ptochicarum emphyteosium pro non soluto canone punimus), fient omnino extranei emphyteomatis, et volentibus praepositis sacrarum domuum licebit praedia aut domos defendere, nulla metuentibus meliorationum redditionem...»

Esta disposición es repetida por la Novela 120, del año 544, también de Justiniano, en su cap. 8:

«Si vero quis aut locator aut emphyteota alicuius rei competentis aut sanctissimae maiori ecclesiae aut alteri venerabili domui in quolibet loco nostrae reipublicae constitutae aut deteriorem faciat rem, quam [quodl aut accepit aut post haec acceperit, aut per biennium non intulerit quod ab eo promissum est emphyteoticum aut locationis canonem,

6 C.4.66.2: «In emphyteuticariis contractibus sancimus, si quidem aliae pactiones in emphyteuticis instrumentis fuerint conscriptae, easdem et in aliis omnibus capitulis observari et de reiectione eius, qui emphyteusin suscepit, si solitam pensionem vel publicarum functionum apochas non praestiterit. Sin autem nihil super hoc capitulo fuerit pactum, sed per totum triennium neque pecunias solverit neque apochas domino tributorum reddiderit, volenti ei licere eum a praediis emphyteuticariis repellere: nulla ei adlegatione nomine meliorationis vel eorum quae emponemata dicuntur vel poena opponenda, sed omnimodo eo, si dominus voluerit, repellendo neque praetendente, quod non est super hac causa inquietatus, cum neminem oportet conventionem vel admonitionem expectare, sed ultro sese offerre et debitum spontanea voluntate persolvere, secundum quod et anteriore lege nostri numinis generaliter cautum est. Ne autem ex hac causa dominis facultas oriatur emphyteutas suos repellere et reditum minime velle suscipere, ut ex huiusmodi machinatione triennio elapso suo iure is qui emphyteusin suscepit cadat, licentiam ei concedimus attestatione praemissa pecunias offerre hisque obsignatis et secundum legem depositis minime deiectionis timere periculum». 
damus licentiam venerabili domui, ex qua locatio aut emphyteosis facta est, et quae debentur sola pro praccedenti tempore et antiquum statum locatae sive emphyteoticae rei exigi et eici de emphyteosi sive locatione, non valente de emponematis actionem aliquam contra venerabiles domos movere...»

\section{LA ENFITEUSIS EN LAS PARTIDAS}

La enfiteusis aparece regulada en las Partidas de Alfonso X en la ley $3^{\mathrm{a}}$ del título $14^{\circ}$ (De las cosas de la Eglesia que non se deben enagenar) de la Partida $1^{\mathrm{a}}$, donde se hace alusión a la enfiteusis de bienes inmuebles eclesiásticos, y en las leyes $28^{\mathrm{a}}$ y $29^{\mathrm{a}}$ del título $8^{\circ}$ (De los logueros et de los arrendamientos) de la Partida $5^{\mathrm{a}}$. La regulación que estas leyes hacen de la enfiteusis tiene un origen

7 Partidas 1.14.3 (ed. RAH, Madrid, 1807, I, p. 393): «Enfitéosis es manera de enagenamiento de que ficimos emiente en la tercera ley ante desta, et es de tal natura que derechamiente non puede ser llamada vendida nin arrendamiento, como quier que en sí haya natura de amas á dos, et ha lugar este enagenamiento en las cosas que son raices et non en las muebles, et facese con voluntad del señor de la cosa et del que la recibe, en esta manera; que el recebidor ha luego de dar de mano al otro dineros ó alguna otra cosa cierta segunt se avinieren que es como manera de precio que ha de fincar por suyo quitamiente, et el señor de la cosa débela enagenar al otro á tal pleyto quel dé cada año dineros ó otra cosa cierta en que se avinieren; et puédese facer tal enagenamiento como este para siempre ó para tiempo cierto, et ha de ser fecho por carta de escribano público ó del señor que lo da, et despues deso non se puede destaiar, pagando cada año el que tiene la cosa aquello á que se obligó. Et si por aventura alguno toviese á enfitéosis cosa que pertenesciese á la eylesia, et estodiese por dos años ó poco tiempo mas que non pagase lo que prometió de dar cada año, puedegelo toller el perlado ó aquel á quien pertenesce la cura de las cosas de la eglesia sin otro juicio. Et si naciese contienda sobre este poco tiempo demas de los dos años, debe ser librada por alvedrio del judgador del lugar: et aquellas heredades pueden dar á enfitéosis á aquel que viere el obispo ó el cabildo que mas provecho es de la eglesia en las dar que en las tener».

Partidas 5.8.28 (ed. RAH, III, pp. 234-235): «Contractus enfiteuticus en latin tanto quiere decir en romance como pleyto ó postura que es fecha sobre cosa raiz que es dada á cienso señalado para en toda su vida de aquel que la rescibe ó de sus herederos, segunt que se avienen por cada año; et tal pleyto como este debe seer fecho con placer de amas las partes et por escriptura, ca de otra guisa non valdrie. Et otrosi deben seer guardadas todas las convenencias que fueren escriptas et puestas en él. Et porque este pleyto es mas semejante a los logueros que á otro contrato ninguno, por ende fablamos en este título dél, et decimos que si la cosa que es dada á cienso se perdiese toda por ocasion, asi como por fuego, ó por terremotos, ó por aguaducho ó por otra razon semejante, que tal daño como este pertenesce al señor della et non al otro que la hobiese asi rescebida, et de aquel dia en adelante non serie tenudo de darle cienso ninguno. Mas si la cosa non se perdiese de todo por aquella ocasion, et fincase quanto la ochava parte della á lo menos, entonce tenudo serie de dar el cienso cada año por ella asi como lo habie prometido. Et aun decimos que si la cosa que es dada á cienso es de eglesia ó de órden, si aquel que la asi tenie, retovo la renta ó el cienso por dos años que lo non diese, ó por tres años, si fuese de home lego que non fuese de órden, que dende adelante los señores della sin mandado del juez gela pueden tomar. Pero si despues destos plazos sobredichos quisiere pagar la renta por sí sin pleyto ninguno fasta diez dias, débegela rescebir el señor de la cosa, et entonce non gela debe tomar: et si á ninguno destos plazos non pagare la renta, entonce tomarle puede la cosa el señor maguer nol pidiese el cienso él por sí nin otri por él; ca entiéndese que el dia del plazo á que debie pagar la renta, la demanda por el señor et aplaza al otro que la paguen.

Partidas 5.8.29 (Ibídem, pp. 235-236): «Enagenar et vender puede la cosa aquel que la rescebiere 
claramente romano-bizantino, basada en las normas ya examinadas de las Instituciones de Justiniano, 3.24.3, del Codex, 4.66 (De emphyteutico iure) y en las Novelas 7 y 120 del Emperador Justiniano.

La enfiteusis en las Partidas es un derecho real por virtud del cual el propietario de un bien inmueble cede a otro el goce y la disponibilidad de dicho bien, a perpetuidad o por largo tiempo, asumiendo el cesionario o enfiteuta la obligación de pagar un canon anualmente. Así se expresa la ley $28^{\mathrm{a}}$ de Partidas, 5.8:

«Contractus enfiteuticus en latin tanto quiere decir en romance como pleyto ó postura que es fecha sobre cosa raiz que es dada á cienso señalado para en toda su vida de aquel que la rescibe ó de sus herederos, segunt que se avienen por cada año...»

Las Partidas recogen también, al igual que 1. 3.24.3 y C.4.66.1, la problemática de la naturaleza jurídica de la enfiteusis, indicando que es una institución que tiene su propio concepto y contenido. Así se prescribe en P. 1.14.3:

«... et es de tal natura que derechamiente non puede ser llamada vendida nin arrendamiento, como quier que en sí haya natura de amas á dos...»

Esta misma ley preceptúa que es un contrato y un derecho que tiene como objeto bienes inmuebles:

«... et ha lugar este enagenamiento en las cosas que son raices et non en las muebles...»

El contrato de enfiteusis, de acuerdo con la normativa de la ley $28^{\mathrm{a}}$ de Partidas 5.8 , ha de ser realizado por escrito, bajo pena de nulidad, contando con el consen-

á cienso; pero enante que la venda débelo facer saber al señor como la quiere vender, et quánto es lo quel dan por ella; et si el señor le quisiese dar tanto como el otro, entonce la debe vender á él ante que al otro. Mas si el señor dixese que lo non querie dar, ó se callase fasta dos meses que non dixese si lo querie facer ó non, dende en adelante puédela vender á quien quisiere, et nol puede embargar aquel que gela dió á cienso que lo non faga; pero la debe vender á tal home de quien pueda el señor haber el cienso tan de ligero como dél mesmo. Otrosi decimos que este que tiene la cosa á cienso, que la puede empeñar á tal home como sobredicho es sin sabidoria del señor, et entonce quando la enagena tenudo es el señor de la cosa de rescebir en ella á aquel á quien la vende, et de otorgárgela faciendol ende carta de nuevo; et por tal otorgamiento ó renovamiento de pleyto nol debe tomar mas de la cincuentena parte de aquello por que fue vendida, ó de la estimacion que podrie valer si la diese. Mas á otras personas de quien non podiese haber tan ligeramiente el cienso non la puede vender nin empeñar, asi como á orden ó á home mas poderoso que él; ca entonce non valdrie, et perderie por ende el derecho que habie en ella». 
timiento de propietario y enfiteuta. Han de ser guardados todos los pactos establecidos en dicho contrato:

«... et tal pleyto como este debe seer fecho con placer de amas las partes et por escriptura, ca de otra guisa non valdrie. Et otrosi deben seer guardadas todas las conveniencias que fueron escriptas et puestas en él...»

Esta necesidad de escritura para la validez del contrato de enfiteusis también se recoge en la ley $3^{\text {a }}$ de Partidas 1.14 , donde se establece que dicho contrato ha de ser hecho por carta de escribano público o del propietario del inmueble. Y puede hacerse a perpetuidad o por cierto tiempo, según acuerden las partes, aunque es propio de su naturaleza la larga duración, como se establece en P.5.8.28:

«... para en toda su vida de aquel que la rescibe ó de sus herederos, segunt que se avienen...»

La obligación esencial del enfiteuta será el pago al propietario del canon que hayan acordado en el contrato. $Y$ el propietario ha de ceder al enfiteuta el goce y la disponibilidad absoluta del fundo, como vimos que sucedía en el Derecho romano-bizantino.

Con respecto a quién tiene que soportar el riesgo, las Partidas establecen lo que ya se recogía en las Instituciones de Justiniano 3.24.3 y en el Codex 4.66.1, esto es, si el fundo se pierde íntegramente por fuerza mayor, como por fuego, terremoto, inundación, etc., dicha pérdida habrá de soportarla el propietario; pero si el fundo no se pierde en su totalidad, quedando al menos una octava parte del mismo, el enfiteuta no queda liberado del pago del canon. Así se establece en la ley $28^{\mathrm{a}}$ de Partidas 5.8:

«... et decimos que si la cosa que es dada á cienso se perdiese toda por ocasion, asi como por fuego, ó por terremotos, ó por aguaducho ó por otra razon semejante, que tal daño como este pertenesce al señor della et non al otro que la hobiese asi rescebida, et de aquel dia en adelante non serie tenudo de darle cienso ninguno. Mas si la cosa non se perdiese de todo por aquella ocasion, et fincase quanto la ochava parte della á lo menos, entonce tenudo serie de dar el cienso cada año por ella así como lo habie prometido...»

Las Partidas también recogen, en la ley $29^{\mathrm{a}}$ del título $8^{\circ}$ de la Partida $5^{\mathrm{a}}$, el ius praelationis o ius protimeseos del propietario en el caso de que el enfiteuta quiera vender su derecho. Dicho enfiteuta ha de preavisar al dueño de su intención de vender su derecho enfitéutico e indicarle cuánto le quieren dar por ella. Si el 
dueño quiere dar al enfiteuta la cantidad por la que pretende venderla, habrá de ser preferido a cualquier otro vendedor. Si el propietario no quiere dar tal cantidad o no manifiesta su voluntad en el plazo de dos meses, puede el enfiteuta vender su derecho («vender la cosa», dicen las Partidas) a quien quisiere, con tal que sea persona idónea, de quien el señor pueda recibir el canon con la misma facilidad con la que lo recibe del actual enfiteuta:

«Enagenar et vender puede la cosa aquel que la rescebiere á cienso; pero enante que la venda débelo facer saber al señor como la quiere vender, et quánto es lo quel dan por ella; et si el señor le quisiese dar tanto como el otro, entonce la debe vender á él ante que al otro. Mas si el señor dixese que lo non querie dar, o se callase fasta dos meses que non dixese si lo querie facer ó non, dende en adelante puédela vender á quien quisiere, et nol puede embargar aquel que gela dió á cienso que lo non faga; pero la debe vender á tal home de quien pueda el señor haber el cienso tan de ligero como dél mesmo...»

Cuando se ha respetado el ius praelationis del dueño de la cosa sometida a enfiteusis, pero el propietario no ha hecho uso de él, éste habrá de aceptar al nuevo enfiteuta y otorgarle nueva carta de otorgamiento. Por este traspaso del derecho de enfiteusis, el dueño de la cosa no puede cobrar al nuevo enfiteuta más de la quincuagésima parte del precio por el que fue vendida o de su estimación. Como vemos, el texto alfonsino está recogiendo lo prescrito en C.4.66.3.

Termina esta ley $29^{\mathrm{a}}$ prescribiendo que el enfiteuta no puede vender ni empeñar la cosa a persona de la que no pueda recibir el dueño tan fácilmente el canon, ni a orden eclesiástica o persona más poderosa que él. Si así lo hiciera el enfiteuta, dicha venta será nula y perderá el derecho que tenía sobre ella:

«... et entonce quando la enagena tenudo es el señor de la cosa de rescebir en ella á aquel á quien la vende, et de otorgárgela faciendol ende carta de nuevo; et por tal otorgamiento ó renovamiento de pleyto nol debe tomar mas de la cincuentena parte de aquello por que fue vendida, ó de la estimación que podrie valer si la diese. Mas á otras personas de quien non podiese haber tan ligeramiente el cienso non la puede vender nin empeñar, asi como á órden ó á home mas poderoso que él; ca entonce non valdrie, et perderie por ende el derecho que habie en ella».

En cuanto a la extinción por falta de pago del canon acordado, las Partidas siguen lo establecido en C.4.66.2 y en las Novelas 7, cap.3.2 y 120, cap.8. La ley $28^{\text {a }}$ de Partidas 5.8 prescribe que, en el caso de que la cosa objeto de enfiteusis 
fuera de la iglesia o de orden religiosa, si el enfiteuta no paga la renta durante dos años, puede ser expulsado del inmueble. En el caso de bienes seculares, han de transcurrir tres años de falta de pago por el enfiteuta para que el dueño del fundo, sin mandamiento judicial, pueda recuperar el pleno dominio sobre el mismo, extinguiéndose así la enfiteusis. Pero el enfiteuta puede pagar los cánones de los dos o tres últimos años en el plazo del diez días después del vencimiento y el dueño de la cosa debe recibirlos:

«... Et aun decimos que si la cosa que es dada á cienso es de eglesia ó de órden, si aquel que la asi tenie retovo la renta ó el cienso por dos años que lo non diese, ó por tres años, si fuese de home lego que non fuese de órden, que dende adelante los señores della sin mandado del juez gela pueden tomar. Pero si despues destos plazos sobredichos quisiere pagar la renta por sí sin pleyto ninguno fasta diez dias, débegela rescebir el señor de la cosa, et entonce non gela debe tomar: et si á ninguno destos plazos non pagare la renta, entonce tomarle puede la cosa el señor maguer nol pidiese el cienso él por sí nin otri por él; ca entiéndese que el dia del plazo á que debie pagar la renta, la demanda por el señor et aplaza al otro que la pague».

La prescripción de dos años de impago como causa de extinción de la enfiteusis para los bienes eclesiásticos aparece también recogida en P.1.14.3, que hemos de recordar que está en el título De las cosas de la eglesia que non se deben enagenar. En esta ley se establece asimismo que, si transcurren dos años sin que el enfiteuta pague el canon, puede el prelado o aquél a quien corresponda el cuidado y administración de los bienes de la iglesia expulsar al enfiteuta, sin necesidad de juicio. Si surge un pleito sobre ello poco después de pasados los dos años, dicho pleito ha de ser librado según albedrío del juez del lugar:

«... Et si por aventura alguno toviese á enfitéosis cosa que pertenesciese á la eglesia, et estodiese por dos años ó poco tiempo mas que non pagase lo que prometió de dar cada año, puedegelo toller el perlado ó aquel á quien pertenesce la cura de las cosas de la eglesia sin otro juicio. Et si naciese contienda sobre este poco tiempo demas de los dos años, debe ser librada por alvedrio del judgador del lugar...»

Vemos, por tanto, cómo la regulación que las Partidas de Alfonso X hacen de la enfiteusis tiene básicamente como fuentes las Instituciones de Justiniano, 3.24.3 y las Constituciones imperiales del Emperador Zenón y de Justiniano recogidas en C.4.66 (De emphyteutico iure), así como las Novelas 7 y 120, también de Justiniano. 